\title{
Obstáculos e desafios da prática da intercooperação na percepção dos gestores de uma cooperativa de crédito de livre admissão, em Arcos-Minas Gerais
}

\author{
Obstacles and challenges of the practice of intercooperation in the perception of the \\ managers of a credit union of free admission, in Arcos-Minas Gerais
}

\begin{abstract}
Resumo
Neste artigo analisou-se os obstáculos e desafios da prática do princípio da intercooperação na percepção dos gestores de uma cooperativa de crédito de livre admissão em Arcos-Minas Gerais. Destacaram-se, na literatura, Pinho e Palhares (2004); Nami e Barbalho (2016) e Meinem (2016). A pesquisa caracterizou-se como qualitativa descritiva, sendo os dados coletados por meio de questionário, encaminhado via e-mail a 06 gestores escolhidos pelos critérios de acessibilidade e pelo poder de tomada de decisão que possuem. Os dados foram tratados por meio da análise de conteúdo. Os resultados apontam a importância da intercooperação para as cooperativas, devido à possibilidade de crescimento, expansão do cooperativismo, ganhos de escala, redução de custos, fortalecimento no mercado financeiro, entre outros. Embora tenha sido unânime o posicionamento dos pesquisados sobre a viabilidade do princípio da intercooperação, percebeu-se de fato apenas um discurso vazio e distante da realidade das cooperativas.
\end{abstract}

Palavras-chave: Intercooperação; cooperação; cooperativa de crédito.

\begin{abstract}
In this article we analyzed the obstacles and challenges of the practice of the principle of intercooperation in the perception of the managers of a credit union of free admission in Arcos-Minas Gerais. In the literature, Pinho and Palhares (2004) stood out; Nami and Barbalho (2016) and Meinem (2016). The research was characterized as descriptive qualitative, with data collected through a questionnaire, sent via email to 06 managers chosen by the accessibility criteria and the power of decision-making they have. The data were treated through content analysis. The results point to the importance of intercooperation for cooperatives, due to the possibility of growth, expansion of cooperatives, gains in scale, cost reduction, strengthening of the financial market, among others. Although the respondents' position on the feasibility of the intercooperation principle was unanimous, it was perceived in fact only an empty and distant discourse from the reality of the cooperatives.
\end{abstract}

Keywords: Intercooperation; cooperation; credit cooperative.

Joyce Ferreira Rodrigues ${ }^{\mathrm{I}}$, Ana Lucia Magri Lopes ${ }^{\mathrm{II}}$

${ }^{\text {I }}$ Centro Universitario Unihozintes. Belo Horizonte, MG. joyceferreirar@yahoo.com.br

${ }^{\text {II }}$ Centro Universitario Unihozintes. Belo Horizonte, MG. ana.lopes@unihorizontes.br 


\section{Introdução}

O sistema cooperativista é organizado por pessoas e seu objetivo principal está pautado na ajuda mútua, em busca de interesses em comum e voltados para o futuro que se pretende construir em consonância com os ramos cooperativistas. No Brasil, os ramos do cooperativismo que vigorou até 2019 foram modernizados, passando de treze para sete ramos a partir de 2020. Nessa reorganização, alguns ramos se uniram e outros foram ressignificados, ficando assim estabelecidos: agropecuário; consumo; crédito; infraestrutura; saúde; trabalho; produção de bens e serviços; e transporte (OCB, 2019). Destaca-se que o cooperativismo de crédito, atualmente, está na $16^{\mathrm{a}}$ posição no mundo em expressão, apresentando crescimento e desenvolvimento de forma contínua (PORTAL DO COOPERATIVISMO FINANCEIRO, 2020).

As cooperativas, entretanto, estão inseridas em um ambiente complexo, de constante transformação e que, em geral, pode não conseguir de forma isolada desenvolver todas as competências necessárias para o desenvolvimento de suas atividades (GRANDE, 2008).

Considerando os sete princípios universais que regem o cooperativismo, quais sejam, 1) Adesão livre e voluntária (são organizações voluntárias, abertas a todas as pessoas aptas a utilizar os seus serviços e assumir as responsabilidades como membros); 2) Gestão democrática (como organizações democráticas as cooperativas são controladas pelos seus membros, que participam ativamente na formulação das suas políticas e na tomada de decisões); 3) Participação econômica (os membros contribuem equitativamente para o capital das suas cooperativas e controlam-no democraticamente); 4) Autonomia e independência (as cooperativas são organizações autônomas, de ajuda mútua, controladas pelos seus membros); 5) Educação, formação e informação (as cooperativas promovem a educação e a formação dos seus membros, dos representantes eleitos e dos trabalhadores, de forma que estes possam contribuir, eficazmente, para o desenvolvimento das suas cooperativas; 6) Intercooperação (as cooperativas servem de forma mais eficaz aos seus membros e dão mais força ao movimento cooperativo, trabalhando em conjunto, através das estruturas locais, regionais, nacionais e internacionais; e 7) Interesse pela comunidade (as cooperativas trabalham para o desenvolvimento sustentado das suas comunidades através de políticas aprovadas pelos membros (PORTAL DO COOPERATIVISMO FINANCEIRO, 2020, p. 1), a intercooperação torna-se uma aliada que pode agregar valor ao sistema, já que visa estimular as cooperativas ao trabalho em conjunto, complementando suas competências, tornando-se, dessa forma, uma peça fundamental para as cooperativas se organizarem e contribuírem entre si, tendo como objetivo favorecer o negócio da cooperativa em prol dos associados (MEINEM, 2016).

Segundo Oliveira (2006), a estratégia de cooperação, até mesmo entre empresas diretamente concorrentes é, em alguns casos, adotada e pode facilitar à empresa o acesso a novos mercados, além do desenvolvimento de novos produtos e serviços de forma conjunta. Os mais diversos tipos de relacionamentos surgem para buscar atender algum tipo de necessidade ou problema das organizações envolvidas, e são estes problemas que determinam as razões ou motivações para empreender este ou aquele relacionamento.

Nesse contexto a intercooperação tem sido objeto de crescente discussão quanto à sua forma prática de aplicabilidade junto aos profissionais da área. Sob a ótica das organizações cooperativas, a intercooperação poderá contribuir para uma maior aproximação entre as mesmas, desenvolvendo ganhos de escala e redução de custos nos produtos e serviços oferecidos. Ademais, permanecerão competitivas junto ao sistema financeiro, além de construírem formas eficientes de atuação. Para a sociedade, a prática da intercooperação resultará em uma melhor oferta de preços, serviços e facilidade de acesso às cooperativas (MEINEM; PORT, 2014).

Entretanto, as cooperativas concorrem entre si e ficam expostas à fragilidade do sistema cooperativo, uma vez que não está presente a aplicação do princípio da intercooperação, tendo em vista que na prática, as cooperativas ainda atuam individualmente no mercado (KONZEN; OLIVEIRA, 2016).

Há casos de concorrência acirrada no ramo de crédito, onde cooperativas invadem a área de atuação de outras cooperativas, por meio de abertura de postos de atendimento em localidades onde já existem 
sistemas semelhantes, em busca de novos associados (PORTAL DO COOPERATIVISMO FINANCEIRO, 2020).

Nesse sentido, constata-se a importância da intercooperação para o sistema cooperativista. Porém, questiona-se: quais os obstáculos e desafios concernentes à prática do princípio da intercooperação no contexto de uma cooperativa de crédito mineira?

Para responder tal questionamento, delineou-se como objetivo analisar os obstáculos e desafios da prática do princípio da intercooperação na percepção dos gestores de uma cooperativa de crédito em Arcos, Minas Gerais. Esse tema é relevante para a área acadêmica, pois poderá contribuir para ampliar os estudos, uma vez que há escassez de pesquisas que contemplem a percepção dos dirigentes sobre a intercooperação. Outra relevância se vinculou às questões sociais, uma vez que é preciso considerar o contexto social no qual os indivíduos estão inseridos e seu envolvimento no processo. Para as organizações, as contribuições podem ser úteis na reflexão sobre a contribuição da intercooperação no desenvolvimento das cooperativas e no desenvolvimento da cidade em que a cooperativa está inserida.

Este estudo está estruturado em seis seções, considerando esta introdução. Na sequência tem-se o referencial teórico, a metodologia, a análise dos dados, seguida pelas considerações finais e referências.

\section{Referencial Teórico}

\subsection{Cooperativismo e Cooperativismo no Brasil}

O cooperativismo, na perspectiva de Franke (1973), significa o sistema de organização econômica que busca eliminar os desajustamentos sociais originários dos excessos da intermediação capitalista. Para a Aliança Cooperativa Internacional (ACI, 2018), cooperativa é uma associação autônoma de pessoas unidas voluntariamente para satisfazer suas necessidades econômicas, sociais e culturais comuns através de uma empresa de propriedade conjunta e democraticamente controlada.

Nessa mesma vertente, a Organização das Cooperativas Brasileiras (OCB, 2018) aponta que o cooperativismo é uma filosofia de vida que busca transformar o mundo em um lugar mais justo, equilibrado e com oportunidades para os indivíduos, mostrando que é possível unir desenvolvimento econômico e social, produtividade e sustentabilidade, o individual e o coletivo, sendo uma organização baseada na união de pessoas e não de capital visando atender as necessidades do grupo e não do lucro.

Historicamente, Bialoskorski Neto (2006) relata que o cooperativismo e as formas de cooperação são questões antigas na história da humanidade. Existem registros sobre a cooperação e a associação solidária desde a pré-história da civilização, em tribos indígenas ou em antigas civilizações como os babilônicos.

Apesar de o cooperativismo moderno ter iniciado no século XVIII, sua origem oficial data de 1844, surgindo como uma resposta a um momento de crise social. Segundo Schneider (1999) o movimento surgiu como uma reação ao capitalismo industrial nascente, a superação do interesse privado sobre o coletivo e comunitário que trouxe consequências negativas para uma parte da sociedade. Para Pinho (2004), como doutrina, o cooperativismo surgiu em oposição às consequências negativas do liberalismo econômico, sobretudo, na Inglaterra e na França.

Assim, a Revolução Industrial do século XVIII trouxe à tona o cooperativismo moderno. Em meio às condições miseráveis e desumanas, unidas ao enorme contraste com a burguesia, surge em 1844, em pleno regime de economia liberal, a fundação da Sociedade dos Probos Pioneiros de Rochdale (Rochdale Society of Equitable Pioneers), em Manchester na Inglaterra; associação que, mais tarde, seria chamada de Cooperativa (REIS JÚNIOR, 2006).

A Sociedade dos Probos Pioneiros de Rochdale objetivava a comercialização de mercadorias para atender a seus membros, uma vez que as compras eram realizadas em maiores quantidades para fornecimento aos sócios. Tal prática permitia a economia de seus ganhos para formar o capital inicial e construir o primeiro armazém cooperativo, sob fortes regras de conduta. Observa-se, então, a formação de 
um dos maiores movimentos sociais do mundo na busca por melhor qualidade de vida, face o agravamento da miséria da classe operária e a crescente substituição dos trabalhadores por máquinas a vapor (MENEZES, 2004).

A partir da formação da Cooperativa de Rochdale, foram criados os princípios cooperativistas que se baseavam em valores democráticos, voto individual, sociedade aberta, remuneração, distribuição de sobras, educação, neutralidade política e religiosa (MEINEM; PORT, 2014).

No Brasil, a cultura do cooperativismo é observada desde a época da colonização portuguesa. Contudo, foi em meados do século XIX, mais precisamente em 1889, que surgiu a Sociedade Cooperativa Econômica dos Funcionários Públicos de Ouro Preto, sendo uma cooperativa de consumo. Já no século XX, em 1902, surge a primeira cooperativa de crédito, no Rio Grande do Sul. E em 1906, começam a se desenvolver as cooperativas agropecuárias (PINHO; PALHARES, 2004).

As cooperativas de crédito surgiram no Brasil como forma de educação para a poupança. Inicialmente tem-se uma reserva de capital através da realização de vários depósitos, para depois conceder linhas de créditos para os tomadores de empréstimo. Desta forma, as pessoas que não tinham acesso ao crédito passaram a ser atendidas, uma vez que o crédito era limitado a uma pequena camada abastada da sociedade (MENEZES, 2004).

Desde então, conforme o Portal do Cooperativismo Financeiro (2020), a legislação brasileira passou a regulamentar a atividade cooperativista, ainda incipiente. O Decreto do Poder Legislativo n. 1.637, de 5 de janeiro de 1907, foi a primeira norma a disciplinar o funcionamento das sociedades cooperativas, onde elas poderiam ser organizadas sob a forma de sociedades anônimas, sociedades em nome coletivo ou em comandita, sendo regidas pelas leis específicas.

Desta forma, já em 1971, pela necessidade de regulação legislativa sobre o cooperativismo, foi criada a Lei $\mathrm{n}^{\circ}$ 5.764, que define a Política Nacional de Cooperativismo, instituindo o regime jurídico das sociedades cooperativas, incluindo as de crédito. Em 2003, o Banco Central do Brasil (BACEN), através da Resolução $\mathrm{n}^{\circ}$ 3.106, regulou os rumos do cooperativismo de crédito, disciplinando a constituição, autorização para funcionamento, alterações estatutárias e cancelamento da autorização para funcionamento das cooperativas de crédito (BACEN, 2003).

Para o Banco Central do Brasil, a Cooperativa de crédito é uma instituição financeira formada pela associação de pessoas para prestar serviços financeiros exclusivamente aos seus associados. Os cooperados são ao mesmo tempo donos e usuários da cooperativa, participando de sua gestão e usufruindo de seus produtos e serviços (BACEN, 2003).

Existem diversas modalidades de cooperativas, e de acordo com o Serviço Brasileiro de Apoio às Micros e Pequenas Empresas (SEBRAE, 2012), o estatuto das cooperativas de crédito estabelece variadas condições de admissão de associados.

Segundo Pinho e Palhares (2004), os modelos de cooperativas de crédito no Brasil surgiram a partir de padrões estrangeiros, por meio de idealistas que objetivavam solucionar problemas econômicos e sociais, como as Caixas Raiffeisen, Bancos Populares Luzzati e as Cooperativas de Economia e Crédito Mútuo.

Existe, ainda, um conjunto de cooperativas de crédito, que surgiram de acordo com a experiência de cada uma, como cooperativas de crédito agrícola, cooperativas populares de crédito urbano, cooperativas de crédito de trabalhadores de determinada classe ou empregados em empresas públicas ou privadas, cooperativas com seção de crédito, entre outras. Assim, as Resoluções do Banco Central, referem-se simplesmente como cooperativas de crédito, deixando de lado os modelos históricos (PINHO; PALHARES, 2004).

De acordo com o Sindicato e Organização das Cooperativas do Estado de Minas Gerais (OCEMG, 2018), em 2015 existiam no Brasil 6.665 cooperativas distribuídas entre os seus 13 ramos. No ramo crédito contabilizam 976 cooperativas. 


\subsection{Princípio da Intercooperação}

Para os "Pioneiros de Rochdale", a estratégia era a passagem da cooperação no consumo para a produção, da produção para a distribuição e para o governo, sendo que, para alcançar estes dois últimos seriam necessários à assistência de outras sociedades cooperativas, isto é, utilizar da intercooperação (LEITE, 1982).

Para Leite (1982), a intercooperação é elementar para a sobrevivência do cooperativismo. Caso não exista a coesão de esforços pelas cooperativas, a troca de experiências, preferencias nas trocas comerciais, enfim, se não intercooperarem, não há movimento cooperativo, mas sim uma ou outra experiência associativa.

Compreende-se, assim, a importância da troca de experiências entre as cooperativas de crédito para favorecer a implementação de melhorias nos serviços e no atendimento aos cooperados, no qual possibilita com que as cooperativas alcancem melhores resultados e vençam os desafios do cooperativismo de crédito, por meio de formas solidárias e compartilhadas, conforme os valores do cooperativismo (MEINEM; PORT, 2014).

Isso posta, a intercooperação é um dos principais caminhos para o fortalecimento do cooperativismo e a formação em redes cooperativas como ação estratégica para o futuro do negócio (GRANDE, 2008).

Como sexto princípio do cooperativismo a intercooperação estabelece que o trabalho em conjunto possa trazer resultados mais eficazes para os cooperados, colocando o cooperativismo em primeiro plano. E a união de esforços poderá contribuir para a expansão dos negócios através do estabelecimento de regras claras e objetivas (MEINEM, 2016). Logo, a essencialidade do princípio da intercooperação, poderá ser o propulsor de maior aproximação entre as cooperativas de crédito (MEINEM; PORT, 2014).

Por conseguinte a principal finalidade da intercooperação está voltada para a obtenção de ganhos em escala, vantagem competitiva e agregar valor aos produtos e serviços oferecidos pelas cooperativas, não se limitando a oferecer poucos serviços, o que poderá levá-la a perder a competitividade (JERONIMO et al. 2005).

$\mathrm{Na}$ mesma vertente, Oliveira (2006) atesta que quando uma aliança estratégica é realizada de forma otimizada, pode proporcionar diversos resultados às cooperativas parceiras, como: a) expandir a força competitiva de cada uma das cooperativas ou da nova cooperativa eventualmente formada; b) melhor e mais rápido acesso aos recursos tecnológicos, financeiros, comerciais e humanos; c) estruturação e otimização do processo de controle e avaliação; d) compartilhamento dos riscos do negócio; e) agregação de valor e fortalecimento dos produtos ou serviços, redução de custos, criação de novas utilidades nos produtos; f) melhor acesso aos mercados; g) melhorias nos processos produtivos, otimizando instalações e desenvolvendo padrões operacionais; h) aumento da capacidade tecnológica através da criatividade em pesquisa e desenvolvimento; i) identificação e exploração de novas oportunidades; j) aprendizagem conjunta e evolução organizacional; k) melhoria das condições financeiras mediante o incremento de sobras e redução dos custos administrativos e de investimentos.

Para Menezes (2004) cooperar significa trabalhar junto, um com o outro, mais que um ao lado do outro. Tem também, a ideia de que o conjunto pode realizar mais que o indivíduo isoladamente.

Assim, para que a estratégia de cooperação tenha êxito é necessário que haja entre as cooperativas a troca de informações, o estabelecimento de intercâmbio de ideias, o desenvolvimento de uma visão estratégica, a definição clara da área de atuação, a análise conjunta dos problemas e soluções e a definição das contribuições dos parceiros (MEINEM; PORT, 2014).

Segundo Meinen (2016), as boas práticas de gestão devem permear o funcionamento e o crescimento estratégico das cooperativas, preservando a identidade de cada uma, uma vez que as cooperativas são diferentes das demais instituições financeiras e é necessário expor essa diferença para a sociedade. Por meio da intercooperação sistêmica as cooperativas podem construir ações conjuntas que levem ao público os valores e diferenciais do cooperativismo. 
Desta forma, para Nami e Barbalho (2016, p. 51) "se temos o melhor atendimento, taxas atrativas, melhores resultados em relação às instituições financeiras tradicionais e ainda não somos a maior instituição financeira do país, o que falta é abrirmos novos caminhos", utilizando fórmulas que já foram validadas por outras cooperativas, através da intercooperação.

Para Soares, Wegner e Dolci (2016) a criação de redes de cooperação empresarial visa à redução das dificuldades competitivas, produzindo efeitos de escala e favorecendo a negociação com fornecedores e clientes. Desta forma, quanto maior o número de empresas envolvidas nas redes de cooperação empresarial, maior a possibilidade de ganhos competitivos. Observa-se que, em relação aos benefícios verificados nas empresas, o fortalecimento daquelas integradas nas redes de cooperação é maior em comparação com aquelas que não integram o grupo constituído. Contudo, quanto maior o potencial de ganho, maior será a complexidade de gestão.

O conceito de rede é bem difundido no mercado tanto em cooperativas, como também em empresas privadas que se unem em associativismo com a finalidade de ganho em comum através da união de esforços. Um desafio das redes é assegurar que as empresas da rede contribuam para o aumento dos recursos da rede e da eficácia, não importando quais partes são apropriadas por cada empresa (SYDOW; WINDELER, 1998).

Verifica-se assim, que a cooperação pode ser uma estratégia adequada também para as cooperativas, pois através de ações coletivas na forma de redes, as cooperativas aumentam as possibilidades de uma melhor performance. Isso teoricamente encontra respaldo nas sociedades cooperativas, já que o comportamento cooperativo faz parte dessas organizações, associados à cultura de cooperação recíproca, aos princípios cooperativos da cooperação entre cooperativas e aos valores morais (JERÔNIMO et al., 2005). Wegner e Padula (2011), citam diversas estratégias de crescimento que podem ser adotadas, como a captação de novos associados para ampliar a rede e a otimização dos resultados com os novos associados.

A intercooperação pode ser uma das alternativas para o desenvolvimento das cooperativas, uma vez que a formação de redes cooperativas é uma das tendências do cooperativismo contemporâneo (GRANDE, 2008). Contudo, existe uma corrente teórica que entende que o processo de intercooperação pode demorar algum tempo para amadurecer (AGROANALYSIS, 2013).

Dentre os estudos utilizados sobre intercooperação, vale ressaltar a pesquisa desenvolvida por Jerônimo et al., (2005) ao abordarem a intercooperação em rede, no contexto de sete cooperativas de grande porte, apesar dessa pesquisa limitar-se ao ramo agropecuário. Konzen e Oliveira (2016), também contribuíram para o entendimento da intercooperação ao tratarem dessa temática sob uma perspectiva teórica.

\section{Metodologia}

Esta pesquisa de abordagem qualitativa caracteriza-se como descritiva. Denzin e Lincon (2005) asseguram que a abordagem qualitativa tem por objetivo aceitar técnicas interpretativas e instrumentos que admitam analisar um contexto manifesto às pessoas e às organizações. Já a pesquisa descritiva permite ao pesquisador a possibilidade de compreender a relação dos indivíduos com a comunidade pesquisada, o que é fundamental a elucidação das questões investigadas (TRIVIÑOS, 1987).

Realizou-se um estudo de caso em uma cooperativa de crédito com sede em Arcos, Minas Gerais, pertencente ao sistema Sicoob. Segundo Yin (2005), o estudo de caso é uma investigação empírica de uma situação contemporânea dentro de um contexto real, os limites entre o fenômeno e o contexto não estão evidenciados. A escolha desta cooperativa para realização do estudo foi pela análise de que na cidade a qual está inserida possui cooperativas de centrais diferentes e de sistema diferentes o que poderia trazer maior riqueza de informações nas respostas dos sujeitos de pesquisa.

A referida cooperativa foi fundada em 1993, por um grupo de micro e pequenos empresários do município de Arcos. Iniciou suas atividades tendo como público alvo os comerciantes da região e, em 2015, o Banco Central do Brasil aprovou sua livre admissão de associados. Sua área de atuação se restringe ao município de Arcos-MG e atualmente, possui somente um ponto de atendimento (sede) na cidade. Conta com aproximadamente 2.589 (dois mil, quinhentos e oitenta e nove) cooperados, em um universo de 36.597 
(trinta e seis mil, quinhentos e noventa e sete) habitantes da cidade de Arcos-MG, de acordo com o último senso realizado em 2010 pelo Instituto Brasileiro de Geografia e Estatística (IBGE, 2010). A cooperativa possui 27 colaboradores, 1 menor aprendiz, 1 estagiário e 4 prestadores de serviços.

Já a unidade de análise, segundo Yin (2005), é o tipo de caso aos quais as variáveis ou fenômenos estudados se referem, e sobre o qual se coletam e analisam os dados. Nesse contexto, a pesquisa teve como unidade de análise os obstáculos e desafios da prática do princípio da intercooperação.

Vergara (2007) considera os sujeitos da pesquisa as pessoas que irão fornecer os dados ao entrevistador. Nesse sentido, os sujeitos desta pesquisa foram três dirigentes, dois conselheiros administrativos e um presidente do conselho de administração da cooperativa pesquisada. Não houve restrição quanto à idade, área de formação, estado civil, tempo de atuação no cargo de tal forma que diferentes posicionamentos sobre a aplicação do princípio da intercooperação pudessem ser examinados. $\mathrm{O}$ critério de seleção dos pesquisados foi pela acessibilidade e pelo poder de tomada de decisão que possuem, sendo identificados de R1 a R6 para preservar suas identidades.

Para a coleta de dados, utilizou-se um questionário contemplando questões abertas, encaminhado via correio eletrônico aos partícipes desta pesquisa, no período de 01 a 07 de dezembro de 2018. Em relação ao tratamento dos dados, optou-se pela análise de conteúdo proposta por Bardin (1979). Essa técnica abarca as iniciativas de explicitação, sistematização e expressão do conteúdo de mensagens, visando realizar deduções lógicas e justificadas a respeito da origem das mensagens.

\section{Apresentação e análise de dados}

Esta seção é destinada a apresentação e análise de resultados. Os respondentes desta pesquisa foram seis profissionais, sendo todos do sexo masculino. Dois deles com nível superior em andamento, e quatro com nível superior completo e pós-graduação na área de gestão. A idade dos entrevistados varia entre 40 a 60 anos e o tempo de atuação no cooperativismo ultrapassa dez anos, porém a experiência nos cargos ocupados apresenta variações. Sendo que dentre os respondentes, um possui vinte e cinco anos de experiência, um possui doze anos, um possui nove anos, outro possui oito anos, um possui sete anos e um possui menos de um ano.

Assim, foram pesquisados profissionais que, de alguma forma, pudessem contribuir para o entendimento dos obstáculos e desafios que a cooperativa de Arcos-MG enfrenta para a aplicação da intercooperação.

\subsection{Aplicabilidade da Intercooperação nas Cooperativas}

Com relação à percepção dos pesquisados sobre as formas de se praticar a intercooperação no sistema cooperativista de crédito, percebeu-se consenso entre os respondentes sobre esta temática. As respostas obtidas indicam que é necessário não somente a troca de experiências entre as cooperativas singulares e centrais, como também a unificação do Sistema Sicoob a partir da junção entre as centrais Crediminas e Cecremge.

A melhor forma de se praticar a intercooperação no sistema é através da troca de experiências entre as singulares e também das centrais (R2).

[...] compartilhamento de ideias e boas práticas via Central, mas, sobretudo acredito que pode ficar ainda melhor a partir do momento que caminharmos para ser um único Sistema Sicoob, iniciando com a união da Central Crediminas com a Central Cecremge para que possa ser estendido às suas singulares $(\mathrm{R} 1)$.

Outros entrevistados aludem sobre a importância do sistema para a prática da intercooperação entre as cooperativas, mesmo que haja concorrência entre elas.

Para uma melhor intercooperação o primeiro passo deverá ser dado através do próprio sistema, pois ainda na ponta há muitas controvérsias dentro de um mesmo sistema tais como cadastro, marca, formato de agências, dentre outras. Quando falamos de 
intercooperação primeiro precisamos pensar em uniformização e as diversidades nestes formatos ainda têm muitas barreiras a serem transpostas (R3).

Deveria partir do sistema, mesmo sendo um só, entre as centrais e as singulares existe uma concorrência entre si, e isto reflete em todos os envolvidos (R5).

Outra colocação indica que a intercooperação é um dos princípios cooperativistas, de suma importância para o crescimento do sistema, cujo objetivo é estimular o relacionamento entre as cooperativas, sendo que unir esforços em busca de benefícios comuns é a principal forma de praticá-la.

De forma geral, esses posicionamentos são reforçados por Leite (1982) ao ressaltar que a intercooperação é elementar para a sobrevivência do cooperativismo. Caso não exista a coesão de esforços pelas cooperativas, a troca de experiências, preferências nas trocas comerciais, enfim, se não intercooperarem, não há movimento cooperativo, mas sim uma ou outra experiência associativa.

Quanto ao que é possível de ser compartilhado entre as cooperativas de crédito, os pesquisados foram unânimes ao mencionarem que a intercooperação pode ser praticada em diversos setores, como cadastro, crédito, atendimento, ações sociais, entre outros, conforme relatos a seguir.

Vários temas poderiam ser compartilhados nas mais diversas áreas de atuação das cooperativas, como: crédito, cobrança, cadastro, atendimento, produtos e serviços, bem como ações sociais e de fomento às comunidades que se encontram inseridas (R1).

No aspecto social várias ações podem ser compartilhadas, porém de forma isolada contribuem, mas não o quanto poderia contribuir se estivéssemos caminhando juntos com o mesmo propósito (R3).

No quesito dificultadores para a prática da intercooperação, alguns dos respondentes indicaram a concorrência como fator preponderante e a desunião entre os dirigentes.

[...] uma dificuldade recorrente é reconhecer o próximo como parceiro e não como concorrente ou adversário [...] (R2).

Vejo um distanciamento muito grande entre as cooperativas principalmente entre gestões o que dificulta o relacionamento e principalmente a intercooperação (R3).

A maior dificuldade em implantar o $6^{\circ}$ princípio do cooperativismo, em Arcos-MG, é a falta de integração, de união, não existe colaboração, falta relacionamento. Isto ocorre, muitas vezes, pela arrogância individual que prevalece sobre o coletivo. A concorrência é outro dificultador, mas, existe (R6).

Falta de integração entre os gestores, são vistas como concorrentes, receio de perda de cooperados, demora na troca de informações cadastrais (R5).

Também foi apontado como dificultador as cooperativas da cidade de Arcos-MG objetivarem segmentos diferentes e também serem filiadas a centrais/sistema diferentes.

Isso pode ser confirmado por Kosen e Oliveira (2016), ao afirmarem que as cooperativas concorrem entre si e expõem a fragilidade do sistema cooperativo, uma vez que não prevalece a aplicação do princípio da intercooperação e ainda complementam que os fatores dificultadores da intercooperação, podem estar relacionados ao desempenho dos dirigentes, uma vez que estes atuam de forma isolada no mercado de crédito, tendo em vista as diferentes questões culturais, políticas e pessoais dos gestores, que defendiam a autonomia das cooperativas.

Já os facilitadores para o exercício da intercooperação entre as cooperativas, na percepção dos pesquisados, acontece por meio do diálogo, troca de informações, conhecimento das afinidades e dos problemas existentes, abstração das vaidades, adequação das agências para executar o que for planejado, entre outros: 
[...] fornecendo uns aos outros, práticas que deram certo, isto considerando as particularidades de cada um [...] (R2)

Para o Sescoop (2016), a cooperação requer uma construção contínua, uma vez que demanda confiança de todos sendo necessário ser transparente e possuir estruturas adequadas.

Para o grupo pesquisado, o princípio da intercooperação poderá aproximar as cooperativas por meio do diálogo, planejamento de ações e trabalho em conjunto, buscando fortalecer o cooperativismo.

[...] demonstrar que a intercooperação é importante para o crescimento e fortalecimento do cooperativismo para enfrentar o mercado [...] (R4).

Desta forma, a intercooperação pode ser um dos principais caminhos para o fortalecimento do cooperativismo e a formação em redes cooperativas como ação estratégica para o futuro do negócio (GRANDE, 2008). Apesar da necessidade de desenvolver melhores práticas da intercooperação, os pesquisados acreditam que as tendências são promissoras, movidas pela própria concorrência do mercado.

[...] mas ainda há muito que avançar nesse sentido, uma vez que exigirá aperfeiçoamento no mercado cooperativista, tendo em vista que o mercado agressivo obrigará as cooperativas a se fortalecerem, obrigando a união entre as cooperativas (R2).

A importância da troca de experiências entre as cooperativas de crédito para facilitar a implementação de melhorias nos serviços e no atendimento aos cooperados faz com que as cooperativas alcancem melhores resultados e vençam os desafios do cooperativismo de crédito, buscando formas solidárias e compartilhadas de atuação, de acordo com os valores do cooperativismo (MEINEM; PORT, 2014).

[...] mais empenho por parte dos gestores, diretores das Centrais e Singulares. Deixar de lado a vaidade e seus ideais. Colocar em prática os ideais do cooperativismo acima de tudo, visando fortalecer cada vez mais o sistema cooperativista no Brasil (R2).

Rossi (2005, p. 96), já mencionava que a intercooperação é um princípio básico do cooperativismo e tem como objetivo promover a aproximação entre as cooperativas para a busca de benefícios coletivos. Acrescenta ainda, que "as cooperativas, para servirem melhor o interesse de seus membros e das suas comunidades, devem colaborar por todos os meios com outras cooperativas aos níveis local, nacional e internacional".

Os efeitos maléficos da intercooperação para a maioria dos respondentes não existem, uma vez que é um princípio cooperativista e pressupõe benefícios para o cooperativismo. Contudo, para alguns respondentes existem dificuldades, pois a intercooperação perpassa pela independência das cooperativas entre si, uma vez que cada uma possui estatutos distintos, podendo ser interpretado de formas variadas, além de objetivos diversos. Acrescentam, ainda, a possibilidade de formação de glomerados, com impactos nos princípios democráticos do cooperativismo.

[...] para os administradores há problemas devido à existência de diversos estatutos, com objetivos diferentes, o que dificulta a interação, causando a concorrência. Dificuldade em manutenção de um capital sólido, uma vez que os clientes poderiam levar seu capital para a cooperativa mais vantajosa ou prestativa (R6).

[...] pode ser que a intercooperação concentre poderes excessivos em grupos pequenos e muito fortes, podendo, com isso, enfraquecer os princípios democráticos do cooperativismo. Há risco do cooperado se distanciar daquela participação efetiva que tem tornado o sistema meio impessoal, até com risco de se assemelhar aos conglomerados financeiros privados da atualidade (R5).

Nesse sentido, para Meinen (2016) quando a cooperativa escolhe a intercooperação inclui em sua estrutura área de atividades comuns a todas as entidades que fazem parte do combinado devendo estar voltadas para melhorar sua atuação junto a seus associados. Em outras palavras, embora as cooperativas sejam independentes entre si, fazem parte de uma espécie de conglomerado financeiro cooperativo, com vantagens e assumindo todas as responsabilidades de uma organização considerada como única (MEINEM, 
2016). De outra forma, o que se percebe, pelas colocações dos sujeitos pesquisados, a seguir, são práticas de intercooperação mais flexíveis.

\subsection{Práticas de Intercooperação Positivas Para o Sistema Cooperativista}

Diversas são as formas práticas de intercooperação, na percepção dos respondentes. O engajamento, profissionalismo, diálogos constantes, somados ao espírito de parceria são apontados pelo grupo pesquisado como principais fatores para a prática da intercooperação, devendo ser realizado pela confederação, central e cooperativas. Para um dos respondentes diversas ações inclusive reuniões regionais entre as cooperativas poderá ser uma das formas de praticar a intercooperação.

[...] o compartilhamento de transporte de valores e máquinas de autoatendimento em locais estratégicos, prestação de serviços entre cooperativas e reuniões regionais com o objetivo de alinhar informações e trocar experiências de casos de sucesso, poderá ser uma forma prática de intercooperação entre as cooperativas de crédito (R4).

Praticar a intercooperação seria pensar em tudo que reduza custo, diminua distância geográfica, tudo que seja possível de ser compartilhado. Nesse sentido, segundo o Portal do Cooperativismo Financeiro (2020), a criação da Lei 5.764 de dezembro de 1971, aduz em seu artigo $8^{\circ}$ sobre a importância das cooperativas centrais e federações buscarem formas de organização para prestar serviços econômicos e sociais em maior escala para suas filiadas através da intercooperação de serviços.

As soluções sistêmicas poderão trazer ganhos de escala para as cooperativas por meio da intercooperação. O planejamento e ações conjuntas são unânimes entre os respondentes como facilitador para implantação da prática de intercooperação. Outra situação apontada foi o compartilhamento de terminais de autoatendimento, agências de publicidades, serviços de limpeza, entre outros.

As ações conjuntas ajudarão na prática da intercooperação. Podemos compartilhar terminais de autoatendimento, agências de publicidades, serviços de limpeza, transporte de valores, compra de materiais de expediente, contratação compartilhada de terceiros, pessoa jurídica para prestação de serviços diversos, isso reduzirá os custos das cooperativas. (R6)

As cooperativas estruturadas no modelo de intercooperação terão, com certeza, uma força econômica maior para competir e atuar no cenário econômico e assim, terão grandes ganhos de escala. (R4)

Soares, Wegner e Dolci (2016) destacam que a criação de redes de cooperação empresarial visa à redução das dificuldades competitivas, produzindo efeitos de escala e favorecendo a negociação com fornecedores e clientes. Desta forma, quanto maior o número de empresas envolvidas nas redes de cooperação empresarial, maior a possibilidade de ganhos competitivos.

Os benefícios para os cooperados viam ganhos de escala, na percepção dos respondentes possibilitarão o atendimento além dos limites da cooperativa de origem, facilidade de acesso ao sistema financeiro, comodidade no atendimento e na solução de problemas.

Entre os ganhos de escala teremos facilidade no atendimento ao cooperado, maior competividade no sistema financeiro, devido a maior agilidade nas soluções solicitadas pelo cooperado, taxas mais competitivas. (R3)

Os pesquisados relataram como vantagens para as cooperativas a fidelização do cooperado, custos compatíveis e ganhos maximizados, cooperativas mais fortes e sólidas, além da geração de sobras.

As cooperativas e o sistema como um todo ganhará com a intercooperação. Teremos cooperados fidelizados, custos menores e consequentemente, maiores sobras nos finais do período. (R1)

[...] dentre todas essas vantagens a maior será as cooperativas mais fortes e sólidas no sistema financeiro brasileiro. (R4) 
Assim, a principal finalidade da intercooperação está voltada para a obtenção de ganhos em escala, vantagem competitiva e agregar valor aos produtos e serviços oferecidos pelas cooperativas, não se limitando a oferecer poucos serviços, podendo perder a competitividade (JERONIMO et al., 2005).

A parametrização dos valores de produtos e serviços poderá evitar a concorrência dentro do sistema cooperativista. De acordo com um dos pesquisados, isso ocorrerá a partir da percepção dos líderes de que somos um sistema integrado. Para outros pesquisados a parametrização poderá ser entendida como cartel e deve ser criada pelas cooperativas de $2^{\circ}$ e $3^{\circ}$ níveis de forma a otimizar processos, diminuir custos e gerar segurança.

Menezes (2004) ressalta que cooperar significa trabalhar junto, um com o outro, mais que um ao lado do outro. Tem também, a ideia de que o conjunto pode se realizar mais que aqueles que trabalham de forma separada dos demais.

O compartilhamento de produtos e serviços nas cooperativas de crédito, para os respondentes, limitou-se a casos de sucessos, informações, marca, troca de experiências e dados básicos dos cooperados. Um pesquisado lembra que a maioria dos caixas eletrônicos do Sicoob fica disponível na agência para uso de qualquer cooperado. Porém, para outro respondente, não há qualquer iniciativa neste sentido.

Em relação ao trabalho em conjunto utilizando a contratação de prestadores de serviços terceirizados com o objetivo de reduzir custos, para a metade dos respondentes essa prática é desconhecida. Para os demais, a contratação de profissionais terceirizados na área de limpeza, fornecimento de lanches, marketing, serviço de segurança, vigilância, ainda está em fase de estudo.

Atualmente, não tenho conhecimento de ação para contratação de serviços terceirizados. (R6)

Diversos serviços terceirizados podem ser contratados em conjunto e estão sendo analisados como: contabilidade, marketing, segurança e vigilância, RH, limpeza. (R1)

De acordo com as afirmações dos respondentes, os empregados das cooperativas poderão prestar serviços comuns entre si através de planejamento, informações compartilhadas, grupos de estudo, soluções comuns às cooperativas envolvidas. Ressaltam ainda, que o trabalho em conjunto no mesmo espaço físico poderá ser um caminho para otimizar recursos, entretanto, precisa ser estudado o método de implantação.

[...] é possível acontecer. Atualmente nos aeroportos várias companhias aéreas realizam o chek in em um único balcão. (R4).

Todavia, a maioria dos respondentes enfatiza que o número de agências e postos de atendimento das cooperativas é insuficiente para atender os cooperados, o que pode ser confirmado pelo relato a seguir.

[...] não é suficiente, uma vez que os cooperados questionam que a maior dificuldade de ser associado está relacionada com a dificuldade de encontrar um caixa eletrônico ou agência para resolver as questões (R5).

Para outro respondente, um número maior de postos de atendimento fortaleceria o cooperativismo na região, podendo servir de incentivo para que mais pessoas se filiem em algum segmento cooperativo.

[...] se estamos sob o mesmo sistema cooperativo que é o Sicoob, todo o tratamento dispensado ao cooperado, e em qualquer agência/PA em nosso país, deveria ser igualitário, o que não é verdade (R2).

Para Nami e Barbalho (2016, p. 51) "se temos o melhor atendimento, taxas atrativas, melhores resultados em relação às instituições financeiras tradicionais e ainda não somos a maior instituição financeira do país, o que falta é abrirmos novos caminhos", utilizando fórmulas que já foram validadas por outras cooperativas, por meio da intercooperação. 


\section{Conclusões}

Percebeu-se que para os respondentes desta pesquisa, a intercooperação é considerada importante para as cooperativas, devido à possibilidade de crescimento, expansão do cooperativismo, ganhos de escala, redução de custos e fortalecimento no mercado financeiro.

Notou-se, pelos resultados desta pesquisa que os respondentes, como atuam no conselho e diretoria, possuem uma visão apenas teórica sobre o princípio da intercooperação. Dessa forma, foram apresentados diversos exemplos em que se poderia aplicar na prática o princípio da intercooperção, mas quando questionados sobre a existência de tal situação, não sabiam ou eram desconhecidas para a maioria dos respondentes.

Embora tenha sido unânime o posicionamento em apresentar situações de viabilidade do princípio da intercooperação, o que existe de fato é apenas um discurso vazio e distante da realidade das cooperativas. Constata-se que a vaidade e a falta de vontade política dos gestores são entraves para se colocar em prática a intercooperação, uma vez que há estudos nesse sentido, mas a falta de diálogo e planejamento torna a realidade no dia a dia das cooperativas afastada do princípio da intercooperação.

Outro fator analisado entre os pesquisados é a transferência de responsabilidade dos gestores para as centrais ou confederações. O princípio da intercooperação já existe, mas é necessária boa vontade política para uma efetiva aplicação prática.

Verifica-se que o que há de concreto são trocas de informações, casos de sucessos, compartilhamento de caixas eletrônicos, marca, entre outros. Enquanto isso, o serviço prestado para os cooperados está aquém do que o cooperativismo pode oferecer, uma vez que as cooperativas não são parceiras, mas vistas como concorrentes entre si. Não é analisado o potencial de crescimento do cooperativismo e da importância da satisfação do cooperado, deixando de observar a intercooperação como um benefício.

Nesse contexto, os ganhos de escala, melhor oferta de preços, serviços e maior possibilidade de sobras, deixam de ser uma realidade para os cooperados e para a sociedade, uma vez que o princípio da intercooperação ainda se encontra no campo teórico.

Entre os respondentes desta pesquisa, houve convergência na maioria das respostas apresentadas. A percepção entre eles no que se refere a exemplos práticos do princípio da intercooperação é limitada. Este estudo limitou-se também a estudar a intercooperação no âmbito de uma cooperativa de crédito ficando restrito a um grupo de profissionais, o que não permitiu uma visão mais ampla sobre o tema no contexto geral do cooperativismo.

Sugere-se aplicar esta pesquisa para um número maior de profissionais em diferentes níveis hierárquicos englobando outras cooperativas da cidade e comparar a percepção dos respondentes da área operacional com a área executiva da cooperativa, a fim de analisar as percepções sobre a importância da aplicação da intercooperação entre as cooperativas.

\section{Referências}

AGROANALYSIS. Cooperativismo paulista aposta na intercooperação. Set. 2013. Disponível em: http://www.agroanalysis.com.br/9/2013/conteudo-especial/cooperativismo-paulista-aposta-naintercooperacao-especial-cooperativismo\#. Acesso em: 05 de set. de 2018.

ALIANÇA COOPERATIVA INTERNACIONAL - ACI. Disponível em: http://ica.coop/. Acesso em: 04 set. 2018.

BANCO CENTRAL DO BRASIL - BACEN. Resolução do Conselho Monetário Nacional nº 3.106, de 25/03/2003. Disponível em: 
https://www.bcb.gov.br/pre/normativos/busca/downloadNormativo.asp?arquivo=/Lists/Normativos/ Attachments/46578/Res_3106_v5_P.pdf. Acesso em: 05 set. 2018.

BANCO CENTRAL DO BRASIL - BACEN. O que é uma cooperativa de crédito. Atualizado em 10/04/2013. Disponível em: http://www.bcb.gov.br/pre/composicao/coopcred.asp. Acesso em: 05 set. 2018.

BARDIN, L. Análise e conteúdo. Tradução de Luís Antero \& Augusto. Pinheiro. Lisboa: Edições 70, 1979. $281 \mathrm{p}$.

BIALOSKORSKI NETO, Sigismundo. Aspectos econômicos das cooperativas. Belo Horizonte: Mandamentos, 2006.

DENZIN, N. K.; LINCOLN, Y. S. (Eds.). The sage handbook of qualitative reserarch. 3. ed. Thousand Oaks: Sage Publications, 2005.

FRANKE, Walmor. Direito das sociedades cooperativas: direito cooperativo. Saraiva, 1973.

GRANDE, E. D.. Intercooperação: gerando valor para as cooperativas. São Paulo, 2008. Disponível em: https://www.facilinformatica.com.br/Noticias/tabid/

188/ArticleID/1289/Intercoopera\%C3\%A7\%C3\%A3o-Gerando-valor-para-as cooperativas.aspx Acesso em: 03 set. 2018.

INSTITUTO BRASILEIRO DE GEOGRAFIA E ESTATÍSTICA - IBGE. População no último senso 2010. Disponível em: https://cidades.ibge.gov.br/brasil/mg/arcos/panorama. Acesso em: 15 abril 2020 .

JERÔNIMO, F. B.; PEDROZO, E. Á.; FENSTERSEIFER, J. E.; SILVA, T. N. Rede de Cooperação e Mecanismos de Coordenação: a experiência da rede formada por sete sociedades cooperativas no Rio Grande do Sul. Ribeirão Preto: 2005. Disponível em: https://www.researchgate.net/profile/Jaime_

Fensterseifer/publication/228375971_Redes_de_cooperacao_e_mecanismos_de_coordenacao_a_ex periencia_da_rede_formada_por_sete_sociedades_cooperativas_no_Rio_Grande_do_Sul/links/00b4 953242a836a12d000000.pdf. Acesso em: 12 set. 2018.

KONSEN, R.; OLIVEIRA, C. Intercooperação entre cooperativas: barreiras e desafios a serem superados. Rio Grande do Sul, 2016. Disponível em: https:// periodicos.ufsm.br/rgc/article/download/20410/pdf. Acesso em: 03 set. 2018.

LEITE, J. S. Cooperação e intercooperação. 1.ed. Lisboa: livros Horizonte. 1982. 141 p.

MEINEM, E. Cooperativismo financeiro: virtudes e oportunidades. Ensaios sobre a perenidade do empreendedorismo cooperativo. Brasília; Confebras, 2016.

MEINEM, E; PORT, M.. Cooperativismo financeiro: percurso histórico, perspectivas e desafios. Brasília; Confebras, 2014.

MENEZES, A.. Cooperativa de Crédito: o que é e quais seus benefícios. Brasília. Editora Confebras, 2004.

NAMI, M.; BARBALHO, F. Metacooperar. Brasília; Confebras, 2016.

ORGANIZAÇÃO DAS COOPERATIVAS BRASILEIRAS - OCB. Apresentação Institucional 2008. Brasília. Disponível em: https://www.ocb.org.br/ocb. Acesso em: 10 set. 2018. 
ORGANIZAÇÃO DAS COOPERATIVAS BRASILEIRAS - OCB. Ramos do Cooperativismo: conheça nossa nova organização. Disponível em:

file:///C:/Documents\%20and\%20Settings/ana.lucia/Meus\%20documentos/Downloads/Cartilha_Ra mos_2019.pdf. Acesso em: 15 abril 2020.

OLIVEIRA, Djalma de Pinho Rebouças. Manual de Gestão das Cooperativas: Uma Abordagem Prática. São Paulo: Atlas, 2006.

PINHO, D. B.; PALHARES, V. M. A. O cooperativismo de crédito no Brasil: do século XX ao século XXI. Santo André: Editora Confebras, 2004.

PORTAL DO COOPERATIVISMO FINANCEIRO. Cenário Brasileiro. Disponível em: https://cooperativismodecredito.coop.br/cenario-mundial/cenario-brasileiro/. Acesso em: 15 abril 2020.

REIS, Nilson Júnior. Aspectos societários das cooperativas. Belo Horizonte: Mandamentos, 2006.

ROSSI, A. C. S. Cooperativismo: à luz dos princípios constitucionais. Curitiba; Ed Afiliada, 2005.

SCHNEIDER, José Odelso. Democracia, participação e autonomia cooperativa. Unisinos, 1999.

SERVIÇO NACIONAL DE APOIO ÀS MICROEMPRESAS - SEBRAE. 2012. Mapeamento das centrais e redes de negócios. Disponível em: http://www.sebrae.com.br/sites/portalsebrae/. Acesso em: 10 set. 2018.

SERVIÇO NACIONAL DE APRENDIZAGEM DO COOPERATIVISMO - SESCOOP. Cooperativismo de Crédito: Boas Práticas no Brasil e no Mundo. Brasília; Ed. Farol, 2016. SICOOB ARCOMCREDI. Sicoob Arcomcredi. Disponível em:

http://www.arcomcredi.com.br/institucional/quem-somos. Acesso em: 20 set. 2018.

SINDICATO E ORGANIZAÇÃO DAS COOPERATIVAS DO ESTADO DE MINAS GERAIS OCEMG. Cooperativismo. Disponível em: http://www.minasgerais.coop.br/pagina/33/numeros.aspx. Acesso em: 10 set. 2018.

SOARES, W.; WEGNER, D.; DOLCI, P. Fusão como estratégia de crescimento de redes de cooperação empresarial: um estudo de caso em uma rede de farmácias. Revista Ibero-Americana de Estratégia, vol. 15, janeiro/março/2016.

SYDOW, Jörg; WINDELER, Arnold. Organizing and evaluating interfirm networks: a structurationist perspective on network processes and effectiveness. Organization Science, Vol. 9, $\mathrm{n}^{\circ} .3$, May-June, 1998.

TRIVIÑOS, Augusto. Introdução à pesquisa em ciências sociais: a pesquisa qualitativa em educação. São Paulo: Atlas, 1987.

VERGARA, S. C. Projetos e relatórios de pesquisa em administração. 8 ed. São Paulo: Atlas, 2007. WEGNER, D. A., R. M.; PADULA, A.D. Tendências da Cooperação em rede horizontais de empresas: o exemplo das redes varejistas na Alemanha. Revista de Administração da Universidade de São Paulo, 45 (3), 2011.

YIN, R. Applications of case study research. Beverly Hills, CA: Sage Publishing. 1993. 